\title{
The Application of TED Talks in the Integrated English Course Based on Output-driven Input- enabled Hypothesis
}

\author{
Xin Cheng \\ Department of Social Science and Foreign Language \\ Tianjin University Renai College \\ Tianjin, China
}

\begin{abstract}
The Output-driven Input-Enabled hypothesis emphasizes that in the process of teaching, the development of students' English output ability should be given great concern, that is, the ability of speaking and writing in English. TED talks are beneficial supportive resources which are characterized by variety of topics, novelty and originality. This paper provides some constructive suggestions to enhance effective applicability of TED talks resources based on the Output-Driven Input-Enabled hypothesis in the Integrated English Course for English majors. Learning groups are reasonably divided in the classroom teaching and relevant TED Talks are given to students as input content, self-display platforms are built for students as well. It is beneficial for improving the teaching effect of Integrated English Course and enhancing the students' English output ability.
\end{abstract}

Keywords-Output-driven Input-enabled hypothesis; TED Talks; Integrated English Course

\section{INTRODUCTION}

In this era of information explosion, the achievements of the information technology revolution emerge endlessly. With the application of multimedia technology and mobile technology in the field of education, new concepts and modes of teaching, such as Moocs, micro-lectures and flipped classes, are constantly pouring into the classroom teaching of college English. However, college English teachers are faced with greater challenges. On the one hand, they have to make more efforts and spend more time in teaching design before class compared with the traditional way of English teaching. On the other hand, the contemporary college students are mainly post 90 s and even post $00 \mathrm{~s}$. They are open-minded and willing to explore something new. Therefore, classroom teaching of English majors should conform to the development of the times by integrating modern information and technology. The Integrated English Course is one of the basic courses for English majors, whose main purpose is to develop and improve students' overall ability in listening, speaking, reading, writing and translation in English. This course not only lays a solid foundation for English majors to learn literature, linguistics, translation and cross-cultural communication, but also has a profound influence on the their thinking mode and way of learning English when they pursue further education. However, the traditional classroom teaching of the Integrated English Course is faced with a lot of problems and challenges. Some teachers still adopt the traditional teaching mode, which is textbook-centered way of teaching. Teachers tend to focus on the texts and explanation and the understanding of new words and expressions, while oral practices and teacher-student interaction as well as writing exercises are often ignored. As a result, students' ability to produce English is often neglected. In the long run, what the students have learned has become the so-called "dumb English", that is to say they can only read and understand English words and articles, while they are not qualified to speak English fluently or write lucid articles. So it is essential that teachers of Integrated English Course change their teaching mode and made some changes to arouse students' enthusiasms and enhance their output ability.

\section{OVERVIEW OF OUTPUT-DRIVEN INPUT-ENABLED HYPOTHESIS}

In 1981, Krashen put forward the theory of "input hypothesis", emphasizing that comprehensible input is a necessary condition for language acquisition. In 1985, Swain put forward the "output hypothesis", which is a supplement and criticism of the "input hypothesis". In Swain's "output hypothesis", he believes that in order to acquire the language, it is not enough to for learners to rely on language input alone. Learners should be forced to carry out a lot of language output exercises - "pushed output". Comprehensible output, which is the prerequisite for language acquisition plays an important role in improving learners' language ability.

Based on the above theories, by a combination of teaching experiment and experience, Wen Qiufang put forward a new "Output-Driven Input-Enabled" Hypothesis. This hypothesis, which is driven by output and simultaneously aiming at output, emphasizes that input, is the means to accomplish the output task and that the combination of input and output is an integration of learning and using as well. It enables students to improve their ability to complete output by obtaining the necessary input. As many scholars have mentioned, this is a revolutionary 
change of concept in foreign language teaching and the status of language output in second language acquisition is brought to an unprecedented height.

\section{THE INTEGRATION OF TED TALKS AND INTEGRATED ENGLISH COURSE BASED ON OUTPUT-DRIVEN INPUT- ENABLED HYPOTHESIS}

\section{A. The Selection of TED Talks in the Integrated English Course}

Nowadays, with the increasing accessibility and development of educational technologies, teachers of foreign languages are able to explore, share and create teaching materials, among which TED Talks are one of the beneficial supportive resources. TED, founded in 1984, is an acronym for Technology, Entertainment and Design. It is a non-profit organization which provides a wide range of talks online for free distribution featured with "ideas worth spreading". TED speakers from all walks of life are given a maximum of 18 minutes to deliver a speech on scientific, medical, psychological, educational, cultural and academic topics. The conference is also held all over the world, its spread of ideas is more and more global and diversified. Moreover, TED talks are free to watch and download on the Internet. In a word, these videos have also become powerful and effective supplement educational resources to contemporary teaching of both college English and English majors. It is a great indispensable resource to apply to the classroom teaching of the Integrated English Course as well.

There is a varieties of TED talks online, covering almost all fields, including technology, education, psychology, culture, health care and so on. For this huge amount of resources, teachers should select appropriate videos for students as input material. In terms of topics, teachers should try to choose the videos which are related the texts or their life on campus or some latest social and scientific development. These TED talks often have a positive energy that inspire students to reflect and encourages their emotional and mature growth. As far as the time of video are concerned, TED talks of 5-10 minutes are the best choice. On the one hand, it does not take up too much time in class; on the other hand, it keeps students' attention from being bored and distracted. In view of the language of TED talks speakers, teachers should try to select the native English speaker's talks. Because in such videos, speakers have a standard pronunciation, moderate speech speed, which will be easily accepted and imitated by students to improve their own English pronunciation and intonation.

According to the above principles, TED Talks like Lesson on the Good Life (by Robert Waldinger), Don't Eat the Marshmallow Yet! (by Joachim De Posad), Does Schools Kill Creativity? (by Ken Robinson), Living Beyond Limits (by Amy Purdy), Success is a Continuous Journey. (by Richard St. John), A Kinder, Gentler Philosophy of Success (by Alain de Botton), Five Ways to Listen Better (by Julian Treasure), How Language Shapes the Way We Think (by Lera Boroditsky), Keep Your Goals to Yourself (by Derek Sivers), Why 30 is not the new 20? (by Meg Jay ), How Books Can Open Your Mind? (by Bu Qiujing) are given to students as input materials for they are very suitable for classroom teaching and beneficial for students to enhance their English output.

\section{B. Teaching Procedures of TED Talks in Integrated English Course on Output-driven Input-enabled Hypothesis}

In order to improve the English output ability, student cannot always be passive listeners that sit still as audience in the classroom. Students should be encouraged to exercise their output ability. The teaching procedures are listed in the following:

Establish collaborative learning groups basing on students' English levels and their output ability. Before carrying out the output activities, an observer, a speaker and a writer in each group are selected respectively before they undertake the output task. Meanwhile, student's role in the learning groups should be exchanged in different tasks in order to guarantee efficiency and fairness.

- Establishing collaborative learning groups basing on students' English levels and their output ability: Before carrying out the output activities, an observer, a speaker and a writer in each group are selected respectively before they undertake the output task. Meanwhile, student's role in the learning groups should be exchanged in different tasks in order to guarantee efficiency and fairness.

- Before playing the TED talk videos, relevant topics for discussion are given to the students as a warm-up activity of discussion. During the process of group discussion, the observer notes down some key words and sentences then the speaker briefly delivers a summary of main ideas which are provided by observer in class.

- Background information, words and expressions of the TED talks are given to the students before they watch the video.

- Play the TED talk without subtitles the first time and students are required to discuss the main idea or some details of it with their partners in the learning group.

- Play the TED talk video with subtitles for the students.

- Writers in the learning group are required to write a piece of summary or relevant topic after class. Speakers are required to record audios then send them to Wechat Group as output homework.

- A combination of Peers evaluation and teacher's evaluation will be given to the output homework.

The procedures are shown in the following "Fig. 1": 


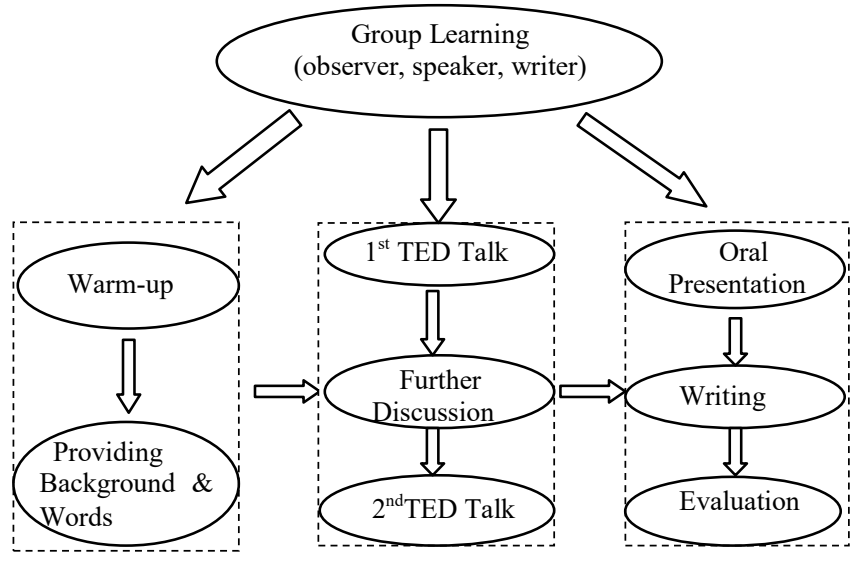

Fig. 1. Teaching Procedures of TED Talks in Integrated English Course on Output-Driven Input-Enabled Hypothesis.

\section{Teaching Practice of TED Talks in Integrated English Course on Output-Driven Input-Enabled Hypothesis}

The author has carried out a series of related TED talks teaching practice on the freshman students of English major in Tianjin University Renai College under the concept of Output-Driven Input-Enabled Hypothesis. Taking the text of unit 9 What is Happiness? in The Integrated English Course as an example, in order to help the students comprehend the text thoroughly, relevant TED Talks are given as auxiliary material and the teaching objectives of this unit are determined as well. (1) Oral output target: Students are able to express their shopping behaviors and habits in English. (2) Writing output target: students are able to illustrate the relationship between happiness and shopping simply.

The TED Talk Less Stuff, More Happiness. (by Graham Hill)is selected as input material. Learning groups of 3 students are established before watching the video and each student is clear about his task. A pre-watching topic for discussion is given to the students: "The so-called double 11 or online shopping festival in China has become the hottest word among Chinese netizens these days. What did you buy on last double 11? Are they useful stuff and really make you happy?" Two to three minutes later, some speakers are chosen at random to share their ideas. Then background information and words like "mantra, space efficiency, digitalize, triple" in this TED talk are provided to the students for a better understanding. Next, the TED talk Less Stuff, More Happiness is played without its subtitles. After watching the video, three observers are selected by the teacher to share the key words and a brief summary of the TED talk. Afterwards, the same TED talk is played with its subtitles for students again. During this time, the video is learned as "intensive reading" or "intensive listening", students will have a clear and thorough understanding of the content of the speech. At last, the output homework is given to the students. The writer of each group is required to complete a 200-word composition on "The Essence of Happiness". Then the teacher asks each study group to exchange and correct their compositions. After the group evaluation, the teacher randomly selected two of the compositions to comment in the class.
After the classroom teaching, Michael Norton's How to Buy Happiness? is uploaded to the WeChat group as oral input material, and the output task of extracurricular autonomous learning is also arranged. Each group is required to record 2-3 minutes of audio with the theme "My view on Happiness" for both students and teachers to evaluate the output task.

After completing the teaching practice of this unit, an interview and exchanges of ideas between the students are organized by the teacher. It is evident that by taking TED talks as the input material in the classroom teaching, students can clearly understand the output tasks in their own learning groups and are aware of their shortcomings in writing and spoken English. Not only can it stimulate the student's enthusiasm, but also it enhances their efficiency and effect for learning English. Moreover, after several units of similar learning, the students are able to imitate the pronunciation, intonation and manner of the TED talk speakers, and perform more calmly and confidently when delivering the output task of presentation. It can be seen that this teaching mode of Integrated English Course based on the OutputDriven Input-Enabled Hypothesis does good to improve students' ability to output English and is beneficial to cultivate students' overall English ability.

\section{CONCLUSION}

The rapid development of information technology has provided a large amount of teaching resources for the Integrated English Course of English majors in contemporary time. How to select resources that are suitable for teaching and learning deserves serious consideration by English teachers.

TED talks are characterized by a combination of being brief, updated and enlightening, which advocates innovative and critical thinking. Thus, they can be used as an excellent teaching resource for the Integrated English Course. Combining the concept of Output-Driven Input-Enabled hypothesis with TED talks, and integrating them into the Integrated English teaching, it accords with the cognitive characteristics of contemporary college students and can stimulate the students' interest in learning English. In the classroom, learning groups are reasonably divided and relevant TED Talks which are related to the contents of text are given to students as input content, self-display platforms are built for students as well. By combining these methods, it creates a vivid atmosphere for language output. The output task is defined and the output practice is strengthened step by step. In this way, the students will be aware of the culture English language and feel the glamour of public speaking. In a word, these teaching practices are beneficial to improve classroom teaching effect and enhance students' English output and their ability for practical application.

\section{REFERENCES}

[1] Carmine Gallo, Talk like TED: the 9 Public - Speaking Secrets of the World's Top Minds, St. Martin's Press, 2014. 3. 
[2] Jeremy Donovan, How to Deliver a TED Talk: Secrets of the World's Most Inspiring Presentations. McGraw - Hill Education, 2013. 10.

[3] Li Ying, Research on the Correlation between Positive Transfer of TED Talks and College Students' Development in Presentation Competency, Journal of Qiqihar University( Phi \& Soc Sci), 2016

[4] Lu Jingjie, Using TED Talks in the Three-dimensional Teaching of English Viewing, Listening and Speaking, Journal of Changshang University, 2013

[5] Stephen E Lucas, The Art of Public Speaking. Foreign Language Teaching and Research Press, 2014

[6] Xiang Yu, Application of TED Talks into College English Teaching, Journal of Jiamusi Vocational College. 2015

[7] Yan Zengli, English Teaching Practice Based on Output- Driven, Input - Enabled Hypothesis - An Empirical Study on Improving Quality of English Language Output, Journal of Tonghua Normal University, 2015

[8] Zhang Chunbai, An Integrated English Course Book 2, Shanghai: Shanghai Foreign Language Education Press, 2011

[9] https://www.ted.com/talks/graham_hill_less_stuff_more_happiness

[10] https://www.ted.com/talks/michael_norton_how_to_buy_happines 